\title{
THE INDUSTRIAL REVOLUTION IN MONOCLONALS
}

I

n one of the most felicitous analogies ever used to portray a scientific idea, Sir Peter Medawar once compared the gramophone with the juke-box as models for instructive and elective explanations of antibody formation. A gramophone accepts external instructions-on discs-just as antigens might program the body to manufacture corresponding, specific antibodies. A juke-box, on the other hand, carries its own predetermined, limited catalogue of tunes. The player simply selects from what is already there, like an antigen calling up the nearest-fit antibody from an existing library of shapes.

Today we can push the analogy even further, by contrasting the $78 \mathrm{rpm}$ records of those times with the modern compact variety. Instead of discs made from masters in batches, one batch often differing from another, we now have total uniformity among every copy of a symphony, Sinatra album, or rock opera. So too with monoclonal antibodies, which bear a similar relationship to the polyclonal antisera of years past. In each case genuine clones have replaced products which, unknown to their users, were heterogenous mixtures.

It's now exactly a year since the first bulk-scale monoclonals went on sale-the $\mathrm{ABO}$ blood grouping reagents marketed in Britain by Celltech Ltd. That was a major landmark, after several American companies had manufactured other high-purity antibodies in small amounts for diagnostic purposes. Judging by the medical journals, though, a much more wide-ranging revolution is now upon us. Only during the past 12 months have clinicians begun to harness the extraordinary qualities of antibodies that can be produced in limitless quantities and with unrivaled purity.

There are now two methods of making human monoclonals. One, based on the historic work of Cesar Milstein and Georges Kohler, is to fuse B lymphocytes with myeloma or lymphoma cells. The other is to transform $B$ lymphocytes into lymphoblastoid cells with the help of Epstein-Barr virus (EBV). Both have been exploited already for making antibodies used in combatting infection. The earlier, hybridoma technique was the choice of Dr. G. Taylor and his colleagues in a recent demonstration that animals given appropriate monoclonals were resistant to respiratory syncytial virus (The Lancet, 1983, ii:976), one of the most prevalent and dangerous of the childhood respiratory disease viruses. Their work, conducted at Georgetown University Schools of Medicine and Dentistry (Maryland) and the ARC Institute for Research on Animal Diseases (Berkshire) showed that two different antibodies completely pro-

Bernard Dixon, Ph.D., is a microbiologist and regular columnist for $\mathrm{BIO} /$ TECHNOLOGY. He is a former editor of New Scientist.

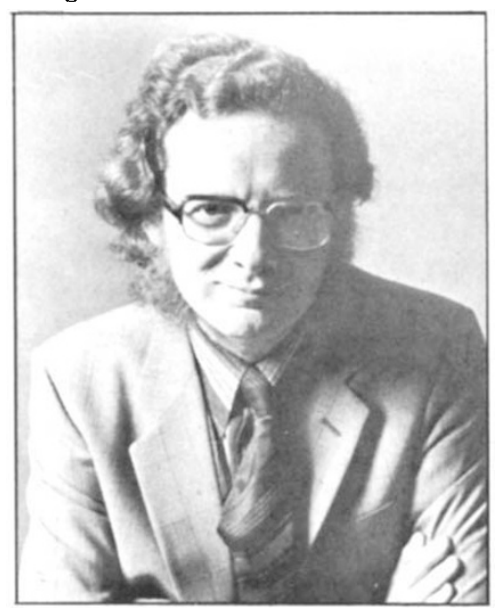

Cenward Dixon, Ph.D. tected mice against the virus. This discovery raises the possibility of effective immunization against the infection.

Another collaboration, between Dr. Michael Epstein at the University of Bristol and University College London co-workers, confirms that the alternative strategy of virus transformation can generate a monoclonal antibody directed against the rhesus D blood group antigen. Epstein and his team have answered criticisms that their product could be hazardous and are now considering using it to prevent hemolytic disease of the newborn. "We conclude that therapeutically active high titre human monoclonal antibodies produced by EBV-transformed cell lines can be easily purified and will be safe to use," they write in The Lancet (1983, i:1040). "Their production will be a significant advance in clinical medicine."

The first clinical trials of an antiblast monoclonal antibody for treating kidney transplant rejection (The Lancet, 1983, 11:1155) - a collaborative effort between the University of California at Los Angeles Medical School and two Japanese hospitals-have provided exciting results. Active rejection was reversed in 17 of the 19 patients tested.

Other groups have developed monoclonals against targets ranging from measles virus to tetanus toxoid. Particularly exciting is the work of Dr. Robert Hartzman and collaborators at Georgetown University School of Medicine (Washington, D.C.), the Naval Medical Research Institute (Bethesda, MD), and the Uniform Services University of Health Sciences (Bethesda, MD). Their innovation is a human monoclonal antibody specific for the capsular polysaccharide of type B Haemophilus influenzae. This organism causes a considerable amount of illness and death-particularly in infants under a year who do not develop immunity when given the corresponding vaccine. The new monoclonal could be precisely what is needed for passive immunization in this age group.

The past year has seen great strides too in diagnostic applications of these uniquely specific homing agents. Following the recognition of tumor-associated antigens, several teams have combined the injection of radiolabeled antibodies with external scanning to detect malignant tissue. Professor Walter Bodmer's group, based at the Imperial Cancer Research Fund, London, has reported success against ovarian, breast, and gastrointestinal cancers. Dr. Paul Farrands's team at the University of Nottingham has located colorectal tumors. And Dr. Richard Rainsbury, with colleagues at London's Ludwig Institute for Cancer Research and the Royal Marsden Hospital, Surrey, have been able to detect bone metastases from breast cancer using similar techniques.

Laboratories on both sides of the Atlantic are even further advanced in using monoclonals to identify "markers" in patients' blood. Substances such as Continued on page 93 
PATENTS (Continued from page 95)

deoxyhypoxanthine. The compounds are useful in the synthesis of a predetermined sequence of RNA with T4 RNA ligase (see above). The preparation of the compounds involves reacting the pyridine salt of adenosine $5^{\prime}$ monophosphate with the nucleoside $5^{\prime}$ phosphate $2^{\prime}-3^{\prime}$ cyclic phosphate. The product is isolated and treated with an enzyme that cleaves the $2^{\prime}$ phosphooxy bond to give the compound, which has the terminal phosphate group on the $3^{\prime}$ carbon of the nucleoside.

\section{EDITORIAL (Continued from page 7)}

cost of travel to "international" meetings in Europe and the U.S. is a great barrier to even the finest academic scientists in Japan. It is far more efficient to send young scientists to train at NIH or Cold Spring Harbor for a year than to spend the equivalent amount of money to travel to four western meetings annually.

When evaluating this policy of stationing Japanese scientists in foreign laboratories, Westerners should also note that there are laws and customs in Japan that make it nearly impossible for the Japanese to benefit from inviting foreign scientists to work and teach in their home settings. Racial pride and tradition make tenure at a major university or advancement in a Japanese research corporation an impossible goal for a westerner in Japan, further isolating the Japanese from the world scientific community. Perhaps this discrimination seems unfair, but it poses a far greater disadvantage to the Japanese than to western research efforts.

A final great myth about Japanese biotechnology that casts a spell over some industrialists is the idea that the Japanese have locked into a way of managing people that will propel them into world leadership in any innovative new technology. The Japanese have demonstrated brilliance in acquiring, developing, and refining applied biological methods, approaching and even surpassing some of the finer western efforts in selected areas of product development. But the system that efficiently builds microchips and random access memories does not necessarily foster creativity in biotechnology. In its special April issue on Japanese biotechnology, this journal will explore the Japanese industrial tradition, founded upon a system of receiving and building on the wisdom of its elders. It is a system that provides stronger rewards for loyal service than for blind achievement, a way of conducting $R \& D$ that seems to frustrate the types of young minds who have helped build the U.S. and European biotechnological base. One of the greatest challenges for the development of applied biology in Japan will be to encourage and give more autonomy to the younger scientists who have the skill and energy to pursue long-term, applications-oriented research. Success in this effort may require that some of the long-cherished Japanese management policies be abandoned for the acceptance of western methods of innovation.

It is in the common interest to explore and destroy the myths that create suspicion and inhibit collaboration between Japanese and western efforts. The long, tense history of ambivalence that has characterized relations between Japan and the major western powers must defer to the notion of world economic progress that can be achieved through collaboration in biotechnology.

\section{- Christopher G. Edwards}

\section{COMMENTARY (Continued from page 27)}

alpha-fetoprotein and carcinoembryonic antigen (CEA), shed by testicular and colorectal cancers, respectively, provide clinicians with an accurate measure of the size of a tumor. Appropriate assays are now beginning to emerge.
And as Dr. Karol Sikora points out, monoclonal antibodies are also set to bring a mini-revolution in histology laboratories. "The easy detection of cancer cells in smears prepared from body secretions such as sputum and vaginal mucous could rapidly lead to automated cytological diagnosis," he writes, "thus reducing its costs and making it available to a wider range of patients" (Nature, 1983, 304:97).

The greatest prize of all, of course, would be a means of fabricating "magic bullets" to destroy malignant tissue in situ. Researchers at Lilly Industries Ltd. in Britain have had initial success in using a CEA antibody, linked with the cytotoxic drug vindesine, to attack human colorectal tumors implanted in mice. Similar, encouraging signs have been reported elsewhere. And as Dr. Reto Obrist of the University Hospital, Basel, Switzerland, observed recently in Trends in Pharmaceutical Sciences (1983, 4:375), once such an approach is thoroughly proven, there will be a double benefit. If highly toxic molecules can be delivered precisely where they are needed, then many potent compounds will once again be candidates for clinical use. The defeat of drug toxicity could prove to be one of the unexpected bounties from the era of the monoclonals. $\boldsymbol{Z}$

\section{FINAL WORD (Continued from page 4)}

for example, computer-controlled fermentations-it should be possible to reduce the manufacturing costs of several high-priced antibiotics from the $\$ 30$ per pound to the $\$ 10$ per pound range. For a typical antibiotic like erythromycin (450 tons per year sales worldwide in 1974) this could represent a profit opportunity of $\$ 18$ million per year.

Similarly, the manufacturing costs for many of the amino acids can be reduced substantially through recombinant DNA and biochemical engineering. For example, a $\$ 5$ per pound reduction in cost for the amino acid phenylalanine (used in aspartame) is entirely reasonable to expect. Given estimates of sales for 1984 in the 2.5 million pound range, such a cost reduction would result in a profit opportunity of $\$ 12.5$ million per year.

For protein products, the manufacturing cost can be expected to be higher because the yield per unit volume of fermentation broth is usually less than for non-proteins, and product purification costs will generally be higher (due in part to the delicate nature of most proteins). At the low end, production costs can be expected to range from $\$ 5$ per pound to $\$ 35$ per pound when yields are good and purification is not critical or problematic. When extremely high purity is required or yield problems exist, production costs could easily be 10 times greater, or $\$ 350$ per pound.

The cost of production of protein products can be lowered from the high to the low ranges using recombinant DNA to increase yields and to aid in purification (by developing strains which secrete the product into the medium, for example). Such reduction in costs from several hundred dollars per pound to under a hundred dollars per pound represents significant opportunities for products in markets of even modest volumes.

I have used these simple examples of existing products to illustrate the point that it is possible to quantify real and current business opportunities for recombinant DNA genetic engineering without relying on dreams of blue-sky breakthroughs. While I believe that many of the exciting opportunities do reside in the future, with new products developed from the use of recombinant DNA technologies in agriculture, pharmaceuticals, and many other industries, the fact is that the recombinant DNA industry represents a real business opportunity right now and is not just another South Sea Bubble. 